\section{Leadership in the digital business transformation}

\begin{tabular}{ccc}
\multicolumn{3}{c}{ Accepted manuscipt } \\
Riitta-Liisa & Laura Bordi & Kirsi Heikkilä- \\
Larjovuori & University of & Tammi \\
University of & Tampere & University of \\
Tampere & Tampere, Finland & Tampere \\
Tampere, Finland & laura.bordi@uta.fi & Tampere, Finland \\
riitta- & & kirsi.heikkila- \\
liisa.larjovuori@uta.fi & & tammi@uta.fi
\end{tabular}

\begin{abstract}
The role of leadership in digital business transformation is a topical issue in need of more in-depth research. Based on an empirical investigation of eight Finnish organizations operating in the service sector, we gain understanding of the role and focus of leadership in the context of digital business transformation. Through a qualitative content analysis of data from 46 interviews, the four main leadership foci of digital business transformation are found: strategic vision and action, leading cultural change, enabling, and leading networks. The findings are discussed in the context of extant research on leadership and digital business development.
\end{abstract}

\section{KEYWORDS}

Digitalization, digital business transformation, leadership

\section{INTRODUCTION}

The development and implementation of information and communication technology (ICT) has had a major impact on business and working life as a whole. According to Kohnke [1], digitization is defined as a process that affects nearly all organizations; therefore, all leaders need to understand its implications on their organization, as well as employees. He argues that new skills and competencies, new forms of leadership, and new organizational capabilities are needed.

While digitization is defined as the process of changing information from analog to digital form [2], the concept of digitalization often is perceived as a broader concept referring to the change process that is driven and enabled by digitization and related technologies. For example, Gartner's IT glossary [3] defines digitalization the following way: "Digitalization is the use of digital technologies to change a business model and provide new revenue and value-producing opportunities; it is the process of moving to a digital business." Digital transformation, on the other hand, is organizational change that arises from the development and application of digital technology in business [4].

For service organizations and their customers, which are this paper's domain, digital business transformation might mean that services become ubiquitous, are constantly and globally available, and are customized to meet each customer's needs. In practice, digital business transformation of services means, e.g., digitalized business-to-business transactions, digitalized customer access, and digitalized core services [5]. These changes, in turn, have a tremendous effect on how work is organized, what kind of work roles and capabilities are needed, and how work is managed (e.g., [6]).

Technological aspects, business-model choices, and the view of strategic capabilities are prevalent in extant research dealing with digital business transformation, but few studies have examined organizational factors and leadership in digital business transformation. For example, extant literature includes research on the importance of leading digital transformation strategically and/or the content of a digital business strategy [7-8]; the new leading positions and roles related to digital transformation in organizations, such as the emergence of the position of chief digital officer (CDO) [9]; and the need for new business models in the digital economy [10].

In this paper, the focus is on leadership in the context of digital business transformation. A case can be made that not many empirical studies deal with the role and function of leadership in the digital transformation process. To address this research gap, this paper's objective is to discuss what kind of leadership is needed to transform an organization into a "digital enterprise."

\subsection{The evolving concept of modern leadership}

The role and execution of leadership has interested scholars for a long time. During the past few decades, the concept of leadership has evolved in several ways. An overall notion in recent extant literature is that the modern leadership research approach focuses not only on the leader, but also on followers, peers, supervisors, work setting or context, and culture. Leadership is viewed as a dyadic, shared, relational, strategic, global, and complex social dynamic. It is no longer described as merely an individual characteristic $[11 ; 13]$.

In addition, it can be noted that the view of leadership reflects how we see the nature of humans. The theory of scientific management is based on the view of "homo economicus," who is individualistic, opportunistic, and self-serving, while modern leadership theories more or less conceive of individuals as being pro-organizational, self-actualizing, and trustworthy [14; 15]. However, the field of leadership studies is pluralistic, i.e., no universal approach to leading exists, and traditional leadership theories (e.g., the idea of scientific management) persist and coexist with more modern and evolving perceptions [16; 17].

Analyses of modern leadership have introduced, for example, authentic leadership, transformative leadership, complexity leadership, and shared leadership (see e.g., [12]). Complexity leadership suggests a paradigm of a complex, interactive dynamic from which adaptive outcomes (e.g., learning, innovation, and 
adaptability) emerge. The conceptual framework of complexity leadership includes three entangled leadership roles: adaptive leadership, administrative leadership, and enabling leadership [11]. All modern leadership theories have some common features, such as an emphasis on the role of social interaction and relational leadership practices.

\subsection{Leadership in digital transformation}

The role of leadership in carrying and supporting an organization through a digital business transition is crucial. As mentioned earlier, extant literature on leadership in the context of digital business transformation is still in its infancy, so not many empirical studies exist. However, organizational-change leadership is a widely researched topic, and extant literature provides many useful notions on digital business transformation. Kohnke [1] proposes a framework for organizational-change management in the context of digitalization. The framework encompasses four cornerstones: 1) aligning leadership; 2) mobilizing the organization; 3 ) building capabilities; and 4) ensuring sustainability. To summarize, digitalizing companies' managers must be able to challenge how their organizations operate, engage their personnel in the process of redefining their work roles, and keep their minds open to the possibility that their own roles will change as well.

The importance of taking a strategic approach to digital transformation is underpinned in the findings of Westerman et al. [18] in their study of 400 large companies around the world. The companies that succeed in embracing digital innovations, called "Digital Masters," possess a clear vision of their digitalization goals and the actions needed to realize them. Moreover, they capitalize on the opportunities to transform their businesses in a more profound manner than just digitalizing existing processes. Westerman et al. [18] propose three main elements of digital business transformation: transforming customer experience (customer understanding, top-line growth, customer touch points); operational processes (digitization, worker enablement, and performance management); and business models (digitally modified businesses, new digital businesses, and digital business globalization). In addition, Hess et al. [7] state that the main reason behind many recent company downturns is that the companies have been unable to develop and utilize novel digital business models.

Based on the aforementioned conceptualizations, the scope of leadership in digital transformation should cover a wide range of issues, from customer experience to human-resource development, as well as their technological foundations. In many models, prioritizing customers' needs is mentioned first, as customers' expectations often are the main driver for digitalization [2;18]. The ability to communicate and even co-create with customers and other stakeholders has become a crucial capability for any modern organization. In terms of digital business transformation, it is even more significant. The organizations that have a more open and customer-oriented culture have been found to progress more rapidly in their digital transformations [19].

\subsection{Changing work and leadership}

While digitalization provides new business opportunities and changes the service offering, as well as how the organization interacts with its customers, it also changes the work inside the organization. For example, the emerging digitalized economy provides working life with more opportunities and greater flexibility in terms of time, place, content, structure, and the process of work. The recognized trends in concurrent working life, enabled by the rapid development of digital technologies, are, for example, that the work is more cognitively complex, team-based, dependent on social skills and technological competencies, time-pressured, and mobile [20].

Workplace communication ecosystems are reformed through the use of real-time communication and collaboration possibilities, e.g., video, instant messaging, web-sharing, and social media [21]. These technologies blur the boundaries between organizations, countries, and industries, and may reduce the need for traditional hierarchies and "command chains" in organizations. In addition, the work itself is increasingly virtual, as are the communication practices, teams, and even leadership. This requires new leadership skills and practices, as leaders need to lead operations, as well as people, in virtual environments (see, e.g., [12;22;23]).

As the business environment becomes more volatile, uncertain, complex, and ambiguous (or VUCA; the term "VUCA-world" is often applied), successful leaders must be more flexible, which includes being more willing to take risks and make decisions more quickly [24]. Therefore, the traditional decision-making processes based on hierarchies and occurring in organizational silos are no longer suitable; an important task for leaders of digitalizing organizations is to reform and steer decision-making practices and organizational structures (including the role and nature of leadership as a whole) toward models that are more agile and flexible [25]. Moreover, it has been argued that the automation of business processes and the use of big data and artificial intelligence (AI) in decision-making increase procedural transparency in the organization [26]. In addition, the use of social platforms and asynchronous communication channels affects the culture and communication within the organization, and as such, the role of leaders as well. New forms of information sharing may even make managers and directors feel that they are losing control, which could increase the risk of leaders resisting technological change [25].

In this research paper, the concept of leadership comprises all activities and processes aimed at directing and mobilizing an organization's resources to reach its goals. The focus is on the role and tasks of leadership in digital business transformation. Leadership, as it is approached in this paper, comprises personnel in formal managerial roles within organizations, as well as other members of the organization or groups of organizations. Dovetailing with the previously mentioned theories on modern leadership, we assume leadership to be in continuous interaction with organizational strategy, structure, culture, and processes. The research question we aim to answer in this paper is: What kind of leadership did interviewees consider to be needed in digital business transformation? 


\section{METHODS}

\subsection{Data Collection}

The data utilized in this paper were collected as part of a mixedmethods research project to study organizations' digitalization processes from different perspectives. Data used in the study were gathered from questionnaires, interviews, participant observations, and group discussions. In spring 2016, 46 interviews were conducted at the beginning of the research project, then analyzed. The objective of the interviews was to gain an overall understanding of how participating organizations' representatives see the digitalization process in their organizations. The interviews totaled 2,460 minutes.

\subsection{Participants}

All participating organizations had shown interest in developing digital solutions for their operations, as they all decided to participate in this action-research project aimed at studying and advancing digital business development. The organizations vary, from small private companies to large public organizations. The companies were selected based on their interest in participating, as well as their diversity. All the organizations operate in the service sector. Participating organizations include six private companies from various fields (insurance, banking, consulting, real estate management, financial administration services, and retail) and two public organizations (tax administration and pension insurance). Four of the private companies are considered large enterprises by Finnish standards (250 or more employees), and two are small and medium-size enterprises (SMEs). The large companies operate in the fields of banking, insurance, financial administration services, and retail, while the SMEs represent consulting and real estate management. The interviewees include personnel in top management, marketing, service development, IT services, and human resources. The number of interviewees in each participating organization varies between four and eight. Twenty-nine of the interviewees were men, and 17 were women.

\subsection{Data Analysis}

All the interviews were recorded and transcribed. The main theme of the interviews was the phenomenon of digitalization and its practical implications in each organization. Qualitative content analysis (see e.g., [27]) of the interview data was conducted to determine how the informants address leadership in relation to digital business transformation. Content analysis consists of interpreting data by identifying and forming recurrent themes [28]. The data were analyzed in three phases. At first, all interviewees' discussions covering leadership were identified and marked. In the second phase, a researcher read the marked sections and wrote down keywords about the discussions on leadership in digital business development. After that, the researcher read the data two more times, identified concurrent subjects, and formed preliminary themes. Then another researcher analyzed the leadership-centric parts of the interviews independently and formed themes. The results of these two analyses then were compared. They were similar, although the last classification was a bit more detailed. The two researchers then discussed the analytical process and preliminary results, ending up with four main categories, as in the first analysis, and adding sub-themes based on the second analysis.

\section{RESULTS AND DISCUSSION}

In the analysis, four main categories of digital-transformationrelated leadership foci emerged: strategic vision and action, leading cultural change, enabling, and leading networks. Three of the four categories (strategic vision and action, enabling, and leading networks) were divided further into two sub-themes to bring out nuances in the digital-transformation discussions. The themes are summarized in Table 1 and examined in more detail in the following paragraphs. The results are presented with illustrative quotations from the interviewees. To secure the anonymity of the participating organizations and interviewees, codes are used as identifiers. The two public organizations are coded as public organization 1 or 2 , the two SMEs are marked as SME 1 or 2, and the four large companies as large company 1-4. The number for each organization was assigned randomly. In addition, the interviewees were given participant numbers ranging from one to eight, depending on how many interviewees from each company participated. For example, "i4, public organization 2" means interviewee No. 4 from public organization No. 2.

Table 1: Leadership foci in digital business transformation

\begin{tabular}{|c|c|c|}
\hline Theme & Sub-themes & Description of themes \\
\hline \multirow[t]{2}{*}{$\begin{array}{l}\text { Strategic } \\
\text { vision and } \\
\text { action }\end{array}$} & $\begin{array}{l}\text { Strong vision } \\
\text { and clear goals }\end{array}$ & $\begin{array}{l}\text { Digitalization as an } \\
\text { integrated, strategic focus } \\
\text { Clear communication of } \\
\text { direction }\end{array}$ \\
\hline & $\begin{array}{l}\text { Commitment } \\
\text { and investment }\end{array}$ & $\begin{array}{l}\text { Top management } \\
\text { commitment } \\
\text { Financial investments } \\
\text { Allocated time } \\
\text { Recognizing the } \\
\text { significance of roles and } \\
\text { positions related to digital } \\
\text { business transformation } \\
\text { (e.g., recruitments) }\end{array}$ \\
\hline $\begin{array}{l}\text { Leading } \\
\text { cultural } \\
\text { change }\end{array}$ & - & $\begin{array}{l}\text { Remolding mindset } \\
\text { Creating culture for } \\
\text { innovation (e.g., creativity, } \\
\text { risk-taking, } \\
\text { experimentation, piloting, } \\
\text { agile processes) } \\
\text { Learning to fail }\end{array}$ \\
\hline Enabling & Coaching & $\begin{array}{l}\text { Motivating and inspiring } \\
\text { employees to achieve } \\
\text { objectives }\end{array}$ \\
\hline
\end{tabular}




\begin{tabular}{|c|c|c|}
\hline & \multirow[b]{2}{*}{$\begin{array}{l}\text { Promoting } \\
\text { participation }\end{array}$} & $\begin{array}{l}\text { Encouraging employees to } \\
\text { be active and autonomous }\end{array}$ \\
\hline & & $\begin{array}{l}\text { Creating space and } \\
\text { opportunities for } \\
\text { participation } \\
\text { Engaging employees in the } \\
\text { change process } \\
\text { Sharing responsibility }\end{array}$ \\
\hline \multirow[t]{2}{*}{$\begin{array}{l}\text { Leading } \\
\text { networks }\end{array}$} & $\begin{array}{l}\text { Customer } \\
\text { orientation }\end{array}$ & $\begin{array}{l}\text { Identifying customers' } \\
\text { needs and wants } \\
\text { Increasing the role of } \\
\text { customers in service } \\
\text { production } \\
\text { Digital solutions as } \\
\text { enablers in gaining } \\
\text { customer understanding and } \\
\text { developing customer- } \\
\text { oriented services }\end{array}$ \\
\hline & $\begin{array}{l}\text { Collaboration } \\
\text { and partnership }\end{array}$ & $\begin{array}{l}\text { Looking for new digital } \\
\text { business opportunities with } \\
\text { partners } \\
\text { Gaining needed expertise } \\
\text { and solutions through } \\
\text { collaboration }\end{array}$ \\
\hline
\end{tabular}

\subsection{Strategic vision and action}

The interviewees emphasized the role of strong strategic approaches in digital business transformation. Strategy was viewed as the foundation of all digital business development, and as the backbone of actions related to it: "Strong will and commitment from management that it's in the strategy, I think that's the foundation of it all" (i2, large company). Strategic vision and action were considered to be prerequisites, as well as the first steps, of digital transformation. The discussions on strategy mainly covered two themes: strong vision and clear goals, and commitment and investment. It was emphasized that leadership should contain and communicate clear focus and direction, as well as advance digital development with concrete, strategic actions, such as investments in experimentation, innovation, and expertise.

\subsubsection{Strong vision and clear goals}

The interviewees repeatedly brought up the importance of strategy and strategic leadership in the digitalization process. They discussed how an organization needs a clear focus on where it is heading, and it starts with strategy. Top management must understand the whole picture and lead the transformation in a clear, consistent manner: "The top management has to say it first that this is the direction. And from there, the message should come to a lower and more concrete level. It should be consistent and reliable, that this is our direction" (i6, public organization 1). Having a strong, clearly communicated vision that the whole organization shares was viewed as enabling digital development at all organizational levels. The role of leadership was perceived as highly important in enhancing capabilities related to digital development and change in general.

The interviewees discussed how digitalization has an important role in their organizations' strategy. The strategic emphasis seemed to have grown in recent years. For example, the interviewees discussed how generally, in business, separate digitalization strategies were being merged into existing strategies. Digitalization was perceived to be increasingly integrated into all strategic foci: "Our strategy is all digitalization, well not just, but it has been wellintegrated. We don't have a separate digitalization strategy; instead, we take it into account in everything" (i4, large company 3). Integrating digital business development into an organization's strategy and viewing it as all-encompassing, rather than a separate section, was perceived as key in leading the change process. However, the participating organizations seemed to be at different stages in the strategy process. Some organizations' interviewees were seeing strategic visions implemented into action, while others had a vaguer picture of their organizations' strategies: "I think it (digitalization) has been written into (the strategy). But likely the gentlemen in the top management remember better what has been written down. But in any case, it's a strong part of our service" (i5, SME 2). However, even with organizations that were not necessarily that far along in digital business development, the role of strategy was recognized as highly important.

\subsubsection{Commitment and investment}

The interviewees discussed the importance of top management's commitment to the digital transformation process: "These are not some small circle projects, our digi-projects. Instead, this is part of our strategy, and the board of directors is strongly involved in it" (i5, public organization 2). Commitment was perceived to mean not just talking about digitalization or writing it into a strategy, but specifically taking strategic action to promote digital business development. Some organizations recruited new managers to lead the transformation process. Creating new positions that employ experts responsible for digital development was viewed as an important strategic step: "This Friday, we get a new executive who's in charge of technology. We also have a project director and a director of targeted marketing and customer communication starting. Right now, we are trying pretty strictly to fill all the roles related to digitalization" (i1, large company 1 ). In the interviews, it also was brought up that the strategic significance of some roles and positions had increased or had been recognized in a new way: "Now we no longer have an IT director; we have an ITdigitalization director, who rose to the board of directors, so that, of course, tells about it" (i1, large company 4). Top management's commitment and active participation in the process, which entails recognition of the significance of roles, positions, and tasks related to digital development, were perceived as important.

Strategic action also meant financial investments. The interviewees discussed how no significant transitions are possible unless the organization is ready to invest significantly in digital development: "It hasn't moved forward earlier because it requires investments. It doesn't move (forward) just by deciding that now we're digital. It takes real investments" (i2, large company 4). 
Investments in digital development were perceived as key in succeeding in a competitive business environment: "In order to stand out with digital (services), it requires very successful investments [...]" (i3, large company 2). Some of the interviewees brought up how their organizations had budgeted funds for experimentation through agile, innovative practices to create new solutions: "I'd say that we have this kind of innovation budget" (i1, public organization 1). Budgeting for experiments and innovation was viewed as something that often is overlooked or of secondary importance to other functions, which can obstruct enhancement of digital business functions. Holding onto the innovation budget was viewed as a strategic action to promote digital business development: "For many players, it easily goes that during the year, new thing scome, new regulations come, whatever. Therefore, in the worst case, it eats the innovation cake because the pot for regular system development isn't enough. Then you have to [...] start eating from the innovation pot. And our thought is that we'd rather hold on to that innovation pot, so we can actually build new things." (i2, large company 3 ).

In addition to financial investments, the interviewees also brought up how experimentation and innovation take time. Developing new ideas while working on other projects, or trying to make time for experimentation, was perceived as quite difficult. A lack of time sometimes even was viewed as hindering digital development. The interviewees said it was crucial that time be allocated to address how experimentation should be a central strategic focus of in leadership practices: "The lack of time is pretty often - people here have absurd amounts of work, so experimentation is lacking because there's no time for it. If we experiment on something, we have to think how it's solved that we get the time. It hasn't been understood that the experimentation could bring something incredibly more [...]. The time management [...], there's no ability to do it here, and I think it's a leadership problem" (i4, SME 2).

\subsection{Leading cultural change}

In the interviews, it was brought up that cultural modification is a big part of digital business transformation; therefore, leading cultural change is key. Leadership was viewed as the backbone of organizational culture. The interviewees discussed how digital business transformation requires culture for innovation. This was described as promoting creativity, taking more risks, adopting experimentation and piloting and developing agile processes. At some organizations, changes in organizational structure, especially when operating in a matrix organization, are considered part of cultural change because they require new perspectives and operations. According to the interviewees, one of the main changes needed in organizational culture is learning to try new things in a loose, agile manner without detailed planning and implementation: "Start piloting that digital part in some small way, and when it starts to become more mainstream [...], the core of our thing grows [...]" (i5, SME 1). It was perceived that lighter piloting and experimentation could lead to significant and lasting discoveries, as personnel come up with novel, beneficial, out-of-the-box solutions.

The interviewees also discussed that when creating a culture of innovation, organizations need to learn how to fail, specifically how to handle failure in a constructive and sustainable way. "Wrong shots" were viewed as an inevitable part of experimentation and, therefore, should be handled as such: "The second thing I see is that we should have permission to fail. We can't always score: Some project goes askew, we cut loose from it and accept that it was a wrong shot. Or it could be a shot of learning, that we understood some other thing, and it was valuable in that way" (i3, large company 3). The interviewees recognized the need to view failed experiments as an integral part of the transformation process, i.e., opportunities to learn, develop, and get ahead. Experimentation also was viewed as a continuous iteration process that enables agile service development.

According to the interviewees, mindset and practices can change through a supportive organizational culture. Cultural change is perceived as requiring people-centered approaches. Emotions are involved in the change process, and trust is needed within the organization. Leading cultural change is considered important in getting everyone on board: "We have this cultural modification going on for a second year, and without it, it won't happen because we have a lot of people who have been working here for a long time and done things in a certain way. Therefore, the mindset has to change, how we look at things ahead. I believe it helps that we have that motivation, we just have to work on that cultural side and provide people with tools and understanding on how it's done" (i2, large company 1).

While leading cultural change to create a culture that cultivates innovation was emphasized in the discussions, some interviewees brought up how their organizations are not necessarily leading cultural change in a purposeful and consistent manner. A stated objective to promote creativity might exist, but the practical processes still might be lacking: "There's strong support for staff innovativeness, but it's plain to see that things don't go forward. We do a lot of developing and think, 'yes, yes, we should do this, this, and this,' but then there's no one to make sure that it actually moves forward" (i3, SME 2). While some of the interviewees were seeing a need to build more organic innovation practices into their organizations, such as agile experimentation, others saw a need for more structured and directed activities: "We should regularly have these things related to development of new things. I don't think it's in any way done regularly in our organization. [...] We don't really have any directed activity [for it]" (i2, large company 2). Digital business transformation is viewed as requiring cultural change in all organizations, but what that cultural change means in practice varies. For example, while creativity and innovativeness are widely emphasized as concepts, organizations still might be searching for concrete ways to implement these objectives.

\subsection{Enabling}

Digital business transformation was viewed as requiring development of leadership approaches. Leadership styles and approaches were discussed especially in the context of immediate 
leadership. Hierarchical leadership was perceived as old-fashioned and unsuitable for the new business environment: "Hierarchical leadership isn't possible in the same way in expert organizations. Digital solutions lead to that participatory transformation and to that co-creation-type angle. There should be solutions to those to manage the organization" (i4, SME 1). The role of experts reportedly is increasing in these organizations, which challenges traditional leadership roles and styles. Employees might have more expertise and knowledge in their tasks than the people who lead them, which changes the needs of both employees and leaders, as well as the superior-subordinate relationship.

While it still was considered important for leaders to provide direction and lead the change process in an assertive and consistent manner, the overall role of leaders was viewed as moving toward the role of an enabler who helps and supports employees in reaching their goals. The two main themes covered in the interviewees' discussions on enabling leadership were coaching leadership style and promoting participation. In both of these themes, open relationships that promote dialogue are viewed as central, along with recognizing and treating employees as experts at their own work.

\subsubsection{Coaching}

The digitalizing work and business environment was viewed as needing more of a coaching leadership style. This was perceived as a major change compared with more traditional leadership approaches. Coaching was viewed as supporting employees and helping them succeed in their work: "[...] The task is to primarily be a coach to one's subordinates, to be as close (as needed) for them to succeed. If they don't succeed, then it's up to the supervisor to do something, [...] (then) the coaching hasn't been adequate. Compared to the world before, it's quite a big change" (i1, large company 2). Motivating and empowering employees were viewed as integral aspects of coaching leadership style. In addition, providing feedback and showing support were considered important in helping employees reach their goals. The interviewees discussed how instead of trying to be someone with all the knowledge and answers - which in expert organizations is impossible - leaders need to learn new skills to be able to coach employees on how to find ways to develop. The leaders' task was viewed as finding and learning new ways to motivate, inspire, and encourage employees to achieve objectives: "Now it's no longer that the supervisor knows all trivia. Instead, s/he has to be an expert in getting people to realize how they can improve their own performance. It requires totally new skills" (i2, large company 3 ).

Digital business transformation was perceived as requiring leadership that encourages employees to be autonomous, develop their roles, and come up with new ideas. In the constantly changing digitalizing business environment, it was considered important to encourage employees to be active and autonomous in seeking new ideas and solutions, which was viewed as requiring new skills from leaders, as they generally need to stay in the background and provide facilities, support, guidance, and encouragement to help their often-expert employees succeed: "Leadership is a lot about giving space, creating space, building connections -- taking care of the supportive structures in which people together create their future" (i1, SME 1).

\subsubsection{Promoting participation}

Participatory leadership practices were perceived as important in the digital-transformation process. The interviewees emphasized promoting low hierarchy in the organization, as well as creating space for participation. In the changing environment, it was considered crucial that employees become involved in the transformation process in various ways. Getting staff engaged was viewed as helping to carry out new ideas and practices. For example, some organizations arranged co-creation workshops or utilized change agents to involve staff and get them engaged in the digital-transformation process, while other organizations did not feel that formal efforts to increase participation are necessarily required and that employee participation should be implicit in the culture: "I'd say we have a pretty participative, if not very formal, way of doing things. We don't necessarily have instructions on how to involve your staff to innovate and stuff. It's actually pretty much in our culture, our way of doing things. Because you can't do it any other way" (i4, large company 4). In the interviews, it was emphasized that without actively involving staff, much expertise and potential will be ignored, changes will be half-measures, and in the end, true business transformation cannot be achieved.

The participatory approach from leadership was perceived as being able to grow by doing. The leaders were not necessarily accustomed to involving employees, and the expectation of active participation also could be a foreign concept to employees. The interviewees said leaders need to provide space and opportunities for participation and to encourage employees to bring up their ideas and get involved: "All of these things come consequentially when people just do it in their own work. [...] Then one has the courage to take a stand and present one's own ideas. And when there are enough opportunities for that, everyone gets used to it, that kind of way of working" (i4, public organization 2). Promoting active participation also was viewed as sharing responsibility. Low hierarchy and increased autonomy were perceived as requiring that leaders show confidence in their employees and that employees take responsibility for their work: "I think that in our organizational culture, we have a bit of a need to learn that if people are given more latitude, they should also take responsibility for the outcome" (i1, SME 2). Overall, increasing participation was viewed as requiring new skills and competencies from both leaders and employees.

Even though participatory practices were perceived as highly important, some interviewees brought up the dilemma of involving employees in change processes that might transform their work duties in significant ways, and in the long run, even make their jobs redundant: "Very strongly, we aim to involve our staff [...]. But of course, when we talk about projects that, for example, strongly reshape our way of doing things or something, of course, those are more challenging from the staff's point of view. Because opening those practically means that someone somewhere starts to ponder, 'Wait a minute, will I have a job in the future?' And considering that, the involvement of staff, in general, they always participate if 
possible, but then in some cases, no" (i5, large company 3). However, while the interviewees were aware of the possibly worrisome scenarios with digital development, they also viewed participation as a way to reduce change-related anxiety because it helps them remain in the loop on the change process and decreases uncertainty.

\subsection{Leading networks}

The role of networks in digital business transformation was brought up repeatedly in the interviews. This was perceived to be a major leadership-related change that is needed in the digitaltransformation process. The discussion on networks covered two themes: customer orientation, and collaboration and partnership. The interviewees talked about how organizations cannot focus inward any longer and must reach out to clients/customers more often and in new ways, as well as actively seek partnerships with other organizations to be able to develop operations and services.

\subsubsection{Customer orientation}

The interviewees brought up how the role of customers is changing in the digital transformation. This was viewed as requiring leadership with a stronger focus on customers and new ways of viewing customers' role in the production process. They perceived new hopes, needs, and expectations from customers, requiring new ways of producing and providing services. Customer expectations also were viewed as a driving force for digital business development: "But the demands are coming from customers. [...] In a way, this change in the operational environment also drives us in this digital development [...]" (i2, public organization 1). Customer expectations were perceived as more varied and individualized than before, and digital solutions were viewed as enablers in both gaining customer understanding and developing customer-oriented services: "Digitalization is a possibility [...] to move closer to the customer" (i4, large company 3). In addition, "it's more [about] customer understanding, customer-oriented things, that the digitalization enables" (i8, public organization 1).

Especially when discussing the future of business, customers were perceived as defining products and services. This was thought to require changes in leaders' perspectives, as the supplier-centered approach no longer was viewed as adequate: "The customer's future, it determines what we do in the field and what we do here in the background. I see that the future is that we react to the customer and not that we provide something [...] and hope that they want what we're offering" (i2, large company 1). The participating organizations aimed to involve customers in the development of services, planning and utilizing various ways to involve customers. For example, they were organizing workshops to gain customer insights and using questionnaires to gauge service experiences.

Building customer-oriented practices was viewed as a major focus among leaders in digital business transformation. Even if customers' role in the service-development process was, in some ways, unclear, and not that many practices were established that involved customers, the importance of customer orientation still had been identified within the organizations: "And we come back to that service design, what we can provide to our customers and their customers, customers' customers and customers' staff. That we have talked about here, but maybe we can't exactly make it concrete just yet what it could be" (i1, large company 4). Underestimating customers' role in digital business development was perceived as detrimental: "I don't know how much it brings, but at least you're going to lose if you're not in it" (i7, public organization 1). The interviewees discussed the importance of service design and co-creation in the context of digital business transformation, emphasizing the need to develop new practices for engaging customers. Some organizations were more ahead of the curve in customer orientation than others, but the increasing need for customer-oriented leadership seemed to be widely recognized.

\subsubsection{Collaboration and partnership}

In addition to customers' increased role in digital business transformation, the role of business collaborations and partnerships also was emphasized. Partnerships were viewed as making digital transformation easier, e.g., by making new business possibilities and opportunities available in new ways: "With various partners, we can be present in the digital world; it broadens our availability, our reach" (i2, large company 3 ). The organizations seemed to have recognized that they cannot do everything themselves; therefore, they need to cultivate collaborations. Interviewees often cited a lack of time allotted for digitalization-related business development, and perceived building partnerships and utilizing business partners' knowledge as a possibility for building agile processes to keep up with new developments: "We are working on building an operations model that, in practice, would be some outside quarter that would help us. Because if we, for example, decided that Ifollow startups in addition to myother work, and then when I do it, in a good week for a half-hour and in a bad (week) not at all, it'd be useless. And now there are some contacts with whom we could arrange to build a model, where we would collect information and insight about what's going on" (i5, large company 2).

The interviewees also said that it might not be necessary to digitalize everything inside the organization. Instead, organizations could develop their products and services by facilitating collaboration: "We have, for example, considered possibilities that what if we didn't do everything ourselves? That we would just provide interfaces, for example" (i4, public organization 1). This was perceived as requiring change in thought and attitude because digital business transformation calls for new kinds of expertise and operations that could be gained through new partnerships. The interviewees said organizations should look for new collaboration opportunities openly: “[...] We shouldn't be defensive. Instead, we should be active participants in that world, through partnerships if we can't or don't want to do it (ourselves) [...]. We should be humble because some small innovative company can be really important for us [...]" (i3, large company 3 ). This was viewed as requiring changes in leadership practices, as trust and openness are prerequisites for fruitful partnerships. Opening operations for partners was perceived as a novel way to develop business. However, while co-creation with both customers and partners was viewed as important in digital business transformation, some 
reservations and considerations concerning organizations' readiness for embracing new kinds of open partnerships appeared to surface.

Even if the organizations were not quite there yet regarding cocreational partnerships, the interviewees strongly perceived that new kinds of collaborations were the future of business. Collaboration was viewed as a possibility for new kinds of innovations to benefit customers, as well as organizations.

\subsection{Discussion}

This paper's objective was to recognize key leadership foci in digital business transformation. The study's novelty lies in its context: Leadership in digital transformation was discussed with interviewees who are working in organizations that are going through the change process. The interview data were rich, combining views of organizations at different stages of development. Even though the organizations' stages of digital maturity varied, obvious similarities existed in the discussions of the role and foci of leadership, through which the four themes presented in this paper were recognized. The themes cover leadership at the strategic, cultural, supervisory, and network levels.

The results indicate that strategic vision is an essential starting point for digital business development. The role of strategic vision also has been brought up in extant literature (e.g., [7; 18]). However, although the importance of strategic approaches to digital development was recognized, their practical implementation and requirements were not necessarily understood substantially within all of the participating organizations. It can be recognized that the level of digital maturity differed among the organizations (cf [18]) because despite having business digitalization written into the strategy, not all the organizations carried out the actual strategic operations and actions, e.g., making the investments needed for the digitalization process.

The broad and all-encompassing nature of digital business transformation could be seen in the discussions on changing organizational culture. The role of the leader was considered important in promoting the culture of experimentation, accepting "trial and error," and developing agile practices. These were perceived as aspects of a culture that cultivates innovation, which was considered both a new mindset and a new way to do things collectively. The role of organizational culture also is recognized in extant literature, e.g., Wokurka et al. [29], who argue that one of the main reasons that digital development might not move forward despite strategic alignments is that the organizational culture does not support it.

Interestingly, competencies as such did not come up as a major theme in the interviews, even though in general, they are considered essential in the digitalization process ( $\mathrm{cf}[1])$. However, operational models, piloting, prototyping, and agile practices were mentioned both as something that the organizations need to learn, as well as a means of developing and learning. It can be argued that these capabilities can be viewed as new competencies. In addition, the discussed changes in both mindset and practices also require new skills from both leaders and employees. Therefore, while the role of competencies was not often mentioned explicitly in the interviews, it seemed to be implicitly included. It could be that developing competencies is still quite often understood as formal learning (e.g., organized education and training), and that informal learning, which takes place in everyday work, might not always be recognized as learning.

According to the results, there seems to be a need for various kinds of leadership practices at different organizational levels and in different roles. The discussions on leaders as enablers emphasized the meaning of immediate leadership in the change process. Particularly regarding the role of first-line managers and team leaders, leadership that enables employees to take responsibility, succeed, and develop themselves is considered important. In addition, the need to engage employees to participate in developing various tasks related to digital business development was recognized. While participating in change processes may induce feelings of uncertainty toward the future, it also might increase control over one's work and the change process, as well as provide opportunities to learn. In the rapidly changing work-life environment, with the threat of employment termination everpresent, strengthening staff employability by supporting learning is viewed as part of organizations' sociocultural sustainability ( $\operatorname{cf}[30$; 31]).

While the interviewees discussed leadership approaches and styles in the context of digital business transformation, their views are quite similar to more general approaches presented in extant literature covering leadership within modern organizations (cf [16]). The kind of leadership approaches and practices that participants described in the interviews are reflected, e.g., in servant leadership theory [32] and in literature on engaging leadership [33]. These also have been identified as leadership styles that support well-being at work. A leader no longer is perceived as merely an authority: The role is moving toward one that helps professionals utilize their expertise in reaching organizational goals. Enabling and participatory-leadership practices can be viewed as part of sustainable utilization of human capital, which often is considered the most crucial component of success in today's business environment (e.g., [30; 34]).

In addition to leading organizations' internal changes, leaders also need to focus on outside networks, which comprise both customers and partners. The role of networks is expected to increase as digital business development advances. This creates new varieties of openness and co-creation needs for customers, wider networks, and ecosystems. The role of customer-centricity is emphasized, as well as the need for building and maintaining networks and partnerships. This is in line with extant literature on business digitalization (e.g., $[2 ; 18]$ ). Customers seem to be perceived increasingly as the group that, in many ways, defines the direction of service development. In digitalizing business environment, most organizations need outside help in designing and implementing digital solutions. Service design and other cocreational approaches are considered crucial in leading both customer and partner collaborations. This might require building new skills and mindsets from leaders, especially within 
organizations that traditionally have taken a cautious approach to outside parties, relying mainly on their own expertise.

The interviewees' discussions on the leadership needed in the digitalization process seemed to focus largely on what should be or what is still required for the change process to advance successfully. There was not much description about how conditions are now, although the interviewees do describe, to some extent, the successful directions and operations taken within their organizations. The reason for the emphasis on what is still needed might be that development is still in progress, and how to further advance digital transformation is a major focus within organizations. However, being in the middle of change seemed to make it easy for the interviewees to recognize the key foci of leadership in the digital transformation.

All the participating organizations represented the service sector, a factor that needs to be considered. For example, banking, insurance, and retail, which all were represented in the data, have been considered early adopters of business digitalization [35]. However, participating organizations also included a company from the field of property management, which is considered a rather traditional and slow-moving field. The interviewees represented managerial and expert positions, which probably influenced their views on digital transformation and leadership. If the interviewees were, for example, blue-collar workers, their views on leadership needs could be different. In addition, the role of leadership and perceived development requirements might differ among fields. The role of leadership in digitalization, such as in the manufacturing or construction industries, is an issue that would need its own study. Moreover, our empirical examination comprised both private- and public-sector service organizations. A question might be raised concerning whether/how digital transformation differs among sectors and what kind of impact it might have on leadership needs. In this paper, the question of leadership in digital business transformation was approached broadly to gain a general qualitative view on leadership requirements in service-sector digitalization.

The role and effects of different leadership styles in digital business development could be a springboard for further research. More detailed understanding is needed of the varying roles of firstline managers, human-resource management, and top management in the change process. In addition, leadership and organizational practices that promote sustainability of human resources in the digital transformation process would be another important question for future research.

\section{CONCLUSIONS}

This paper provides an empirical study that examines the role of leadership in digital business transformation. In-depth interviews were conducted with personnel from eight service organizations, then analyzed qualitatively to identify and gain understanding of the main leadership foci in digital transformations within participating organizations. In the analysis, four main themes were recognized: strategic vision and action, leading cultural change, enabling, and leading networks. The results emphasize the broad and comprehensive quality of both digital development and leadership, as the identified themes approach digital transformation-related leadership foci at strategic, cultural, supervisory, and network levels. This study's results provide useful information on organizational digitalization in the service sector, as well as on the complex role of leadership during this process. The study brings up key leadership foci as perceived in organizations going through the digital business transformation process.

\section{ACKNOWLEDGMENTS}

This study is part of a research project funded by Business Finland. The authors would like to thank Laurea University of Applied Sciences for its collaboration on the project, as well as all other participating organizations.

\section{REFERENCES}

[1] O. Kohnke. 2017. It's not just about technology: The people side of digitization. In G. Oswald and M. Kleinemeier (Eds.) Shaping the Digital Enterprise, 69-91. Springer, Waldorf.

[2] E. Schreckling and C. Steiger. 2017. Digitalize or drown. In G. Oswald and M. Kleinemeier (Eds.) Shaping the Digital Enterprise, 3-27. Waldorf: Springer.

[3] Gartner. 2016. IT Glossary. https://www.gartner.com/itglossary/d.

[4] M. Slavova. 2016. Digital Business Transformation. Ikonomiceski i Sotsialni Alternativi 4 (2016), 142-149.

[5] T. J. V. Saldanha, A. Kathuria, J. Khuntia, B. Konsynski, and M. A. Rojas. 2017. Leveraging Digitalization of Services for Performance: Evidence from the Credit Union Industry. International Conference on Information Systems, ICIS Proceedings (2017).

[6] E. Saari, S. Käpykangas, and M. Hasu. 2016. The Cinderella story - a skilled worker's new chance in the digitalization of services. 26th Annual RESER Conference Proceedings (2016), 1059-1071.

[7] T. Hess, C. Matt, A. Benlian, and F. Wiesböck. 2016. Options for Formulating a Digital Transformation Strategy. MIS Quarterly Executive 15, 2 (2016), 123-139.

[8] A. Bharadwaj, O. El Sawy, P. Pavlou, and N. Venkatraman. 2013. Digital business strategy: toward a next generation of insights. MIS Quarterly 37, 2 (2013), 471-482.

DOI: https://doi.org/10.25300/misq/2013/37:2.3

[9] A. Horlacher and T. Hess. 2016. What does a Chief Digital Officer do? Managerial tasks and roles of a new C-level position in the context of digital transformation. 49th Hawaii International Conference on System Sciences (HICSS) Proceedings (2016), 5126-5135. DOI: https://doi.org/10.1109/hicss.2016.634

[10] S. J. Berman. 2012. Digital transformation: opportunities to create new business models. Strategy \& Leadership 40, 2 (2012), 16-24. DOI: https://doi.org/10.1108/10878571211209314

[11] M. Uhl-Bien, R. Marion, and B. McKelvey. 2007. Complexity leadership theory: Shifting leadership from the industrial age to the knowledge era. Leadership Quarterly 18, 4 (2007), 298-318. DOI: https://doi.org/10.1016/j.leaqua.2007.04.002 
[12] B. J. Avolio, F. O. Walumbwa, and T. J. Weber. 2009. Leadership: Current theories, research, and future directions. Annual Review of Psychology 60 (2009), 421-449.

DOI: https://doi.org/10.1146/annurev.psych.60.110707.163621

[13] G. Yukl, A. Gordon \& T. Taber. 2002. A hierarchical taxonomy of leadership behavior: Integrating a half century of behavior research. Journal of Leadership \& Organizational Studies 9, 1 (2002), 15-32.

DOI: https://doi.org/10.1177/107179190200900102

[14] L. Donaldson and J. H. Davis. 1991. Stewardship theory or agency theory: CEO governance and shareholder returns. Australian Journal of Management 16, 1 (1991), 49-64.

DOI: https://doi.org/10.1177/031289629101600103

[15] J. H. Davis, F. D. Schoorman, and L. Donaldson. 1997. Toward a stewardship theory of management. Academy of Management Review 22, 1 (1997), 20-47.

DOI: https://doi.org/10.2307/259223

[16] P. Salovaara. 2011. From Leader-Centricity Toward Leadership: a Hermeneutic Narrative Approach. Ph.D. Dissertation. University of Tampere, Tampere, Finland. Tampere University Press.

[17] S. Kempster. 2009. How Managers Have Learnt to Lead: Exploring the Development of Leadership Practice. Palgrave Macmillan, Basingstoke.

[18] G. Westerman, D. Bonnet, and A. McAfee. 2014. Leading Digital: Turning Technology into Business Transformation. Harvard Business Publishing, Brighton, MA.

[19] R.-L. Larjovuori, J. P. Mäkiniemi, S. Nuutinen, and K. Heikkilä-Tammi. 2017. How are leadership and organizational culture associated with levels of business digitalization? Proceedings IFKAD 2017 - 12th edition of the International Forum on Knowledge Asset Dynamics (2017).

[20] J. Lee. 2016. Impact of ICT on work: Introduction. In J. Lee (Ed.) The Impact of ICT on Work, 1-6. Springer, Singapore.

[21] S. Schallenmueller. 2016. Smart Workplace Technology Buzz. In J. Lee (Ed.), The Impact of ICT on Work, 127-150. Springer, Singapore.

[22] S. J. Zaccaro and P. Bader. 2003. E-leadership and the challenges of leading E-teams: Minimizing the bad and maximizing the good. Organizational Dynamics 31, 4 (2003), 377-387.

DOI: https://doi.org/10.1016/s0090-2616(02)00129-8

[23] A. Malhotra, A. Majchrzak, and B. Rosen. 2007. Leading virtual teams. Academy of Management Perspectives 21, 1 (2007), 60-70. DOI: https://doi.org/10.5465/amp.2007.24286164

[24] N. Horney, B. Pasmore, and T. O'Shea. 2010. Leadership agility: A business imperative for a VUCA world. People \& Strategy 33, 4 (2010), 32-38.

[25] D. Bonnet and P. Nandan. 2011. Transform to the power of digital: Digital transformation as a driver of corporate performance. Consultant's report. Capgemini Consulting.

[26] A. McAfee and M. Welch. 2013. Being digital: engaging the organization to accelerate digital transformation. Digital Transformation Review 4 (2013), 37-47.

[27] M. Q. Patton. 2015. Qualitative Research \& Evaluation Methods. SAGE Publishing, Thousand Oaks.
[28] H.-F. Hsien and S. E. Shannon. 2015. Three approaches to qualitative content analysis. Qualitative Health Research 15, 9 (2015), 1277-1288.

DOI: https://doi.org/10.1177/1049732305276687

[29] G. Wokurka, Y. Banschbach, D. Houlder, and R. Jolly. 2017. Digital culture: Why strategy and culture should eat breakfast together. In G. Oswald and M. Kleinemeier (Eds.), Shaping the Digital Enterprise, 109-120. Springer, Waldorf.

[30] M. Kira and F. M. van Eijnatten. 2008. Socially sustainable work organizations: A chaordic systems approach. Systems Research and Behavioral Science 25, 6 (2008), 743-756.

DOI: https://doi.org/10.1002/sres.896

[31] K. J. Zink and K. Fischer. 2013. Do we need sustainability as a new approach in human factors and ergonomics? Ergonomics 56, 3 (2013), 348-356.

DOI: https://doi.org/10.1080/00140139.2012.751456

[32] D. Van Dierendonck. 2010. Servant leadership: A review and synthesis. Journal of Management 37, 4 (2010), 1228-1261.

DOI: https://doi.org/10.1177/0149206310380462

[33] B. Alimo-Metcalfe, J. Alban-Metcalfe, M. Bradley, J. Mariathasan, and C. Samele 2008. The impact of engaging leadership on performance, attitudes to work and well-being at work: A longitudinal study. Journal of Health Organization and Management 22, 6 (2008), 586-598.

DOI: https://doi.org/10.1108/14777260810916560

[34] G. Hamel. 2007. The future of management. Harvard Business School Press, Boston, MA.

[35] R. Kohli and S. Johnson. 2011. Digital Transformation in Latecomer Industries: CIO and CEO Leadership Lessons From Encana Oil \& Gas (USA). MIS Quarterly Executive 10, 4 (2011), 141-156. 